\title{
The emotional and psycho-social consequences of coronavirus disease-19 pandemic - A glimpse into the post-pandemic society
}

\section{Smrithi Chhabra}

From Associate Professor and Unit Head, Department of Psychiatry, Chirayu Medical College Bhopal, Bhopal, Madhya Pradesh, India

Correspondence to: Smrithi Chhabra, Department of Psychiatry, Chirayu Medical College Bhopal, Bhopal, Madhya Pradesh, India. E-mail: smrithicaj@gmail.com

Received - 25 August $2020 \quad$ Initial Review - 05 September 2020

Accepted - 18 September 2020

\section{ABSTRACT}

The coronavirus disease (COVID-19) pandemic has swept across the globe so devastatingly causing high morbidity and mortality and has brought in its wake, not only social and economic problems but also a myriad of psychological problems which if not addressed properly may contribute considerably to a significant loss of productivity in the society. As per the saying "A sound mind in a sound body," physical and mental health is equally important and interdependent on each other. In the present scenario, unfortunately, with people suffering from physical illnesses, as well as devastating mental sequelae of the pandemic has resulted in social, financial, economic, and emotional uncertainties. Therefore, it is most important to identify and to treat the mental health problems faced by general population, quarantined people, health-care professionals, at-risk-groups, and the victims of COVID-19 pandemic. The mental health problems can be in the form of depressive disorders, various anxiety disorders, stress related disorders, suicide and intentional self-harm, grief reaction, substance abuse (alcohol, tobacco, cannabis, and opioids), and domestic violence. Although, limited resources available to us during these difficult times, this should not dissuade us from ensuring optimal mental health and trying to keep the struggling humanities "sane" during this pandemic. These resources must be used judiciously and appropriately, with necessary modifications (telephonic/audio-video consultations and counseling) to prepare a society which can move forward in the post pandemic era.

Key words: Counseling, Coronavirus disease-19, Emotional problems, Mental health, Psychosocial problems

$\mathrm{O}$ riginating as a small cluster of pneumonia or severe lower respiratory tract infection cases in Wuhan Province of China, the coronavirus disease (COVID-19), or severe acute respiratory syndrome-COV-2 has escalated and snowballed into a widespread pandemic with a myriad of psychological implications. Worldwide the number of cases has sky-rocketed to $23,618,698$ cases and resulted in death of 813,114 people. Around $16,108,613$ people have recovered from the dreaded disease so far. In India, although the start has been low and the "go" has been "slow," yet it has increased to more than 3,300,000 with a mortality of 60,000 cases. Around 25,00,000 COVID-19 positive cases have been cured, yet around 800,000 cases are active in the country. These figures are still high, taking into account the limited COVID-19 testing kits, some degree of under-reporting and asymptomatic or pre-symptomatic or mildly symptomatic cases $[1,2]$.

Any pandemic with ramifications of such vast proportions and such distressing, social, financial, psychological and emotional consequences is bound to have a long lasting effect on the mental health of the people. Although, the impact on mental health may differ between cultures, countries and across continents, some commonalities or a common denominator with regard to mental health implications needs to be outlined [1,2]. The mental health impact may either be due to the direct effect of the pandemic (e.g., high rates of morbidity and mortality) or due to the secondary effects of the pandemic - social, financial, family, and emotional consequences. In addition, the myriad of mental health issues may differ among different subsets of population reports suggest an increase in rates of domestic violence globally due to close proximity and physical confinement within the house due to the lockdown [1,2]. This article attempts to focus on the general mental health implications of this widespread COVID-19 pandemic.

The popular saying, "Fear of the unknown" can be aptly modified to "Fear of the lesser known" in the context of COVID19 pandemic with its share of unpredictability and uncertainty in terms of health, social, emotional, and financial and professional aspects of life $[3,4]$. Various mental health consequences of COVID-19 are as follows.

\section{DEPRESSION}

Among the healthcare workers and health-care seekers alike, the fear of contracting the disease, fear of isolation and quarantine, fear of being away from families, and fear of having to die alone are large contributing factors to depression [4,5]. Factors such as 
overburdened with work, inadequate or lack of availability of PPE kits and N-95 mask, inadequate protection, and fear of contracting the disease while discharging one's duties, long working hours, and "Burn Out Syndrome" contribute to depression [5]. In many countries, the doctors and nurses are on isolation duty for 14 days, followed by a quarantine period ranging from 7 days to 14 days. To safeguard their loved ones, many doctors and nurses may avoid going home which may lead to feeling of despair and depression [5]. Similarly, among the survivors of the pandemic, "survival guilt" may also play a great role in contributing to depression. While in victims who have contracted the disease and are in the late stages, depression may arise due to the thought of not seeing the family members, denial of proper last rites, and denial of authorities to hand over the body $[4,5]$.

\section{Anxiety and Stress}

The COVID-19 pandemic can lead to cognitive, emotional, somatic, autonomic, and behavioral symptoms of anxiety which may be present in varying degrees among the general population at risk. Cognitive symptoms include poor concentration, memory problem, a feeling of helplessness, and a feeling of loss of control. Emotional symptoms include fear, apprehension, a feeling of dread or impending doom, anger outbursts, and irritability. Somatic symptoms can manifest as insomnia, aches and pains, loss of appetite, and loss of libido. Autonomic symptoms can be in the form of palpitations, tremors, urinary urgency, and gastrointestinal irritability. Behavioral symptoms of anxiety can manifest as aggressive behavior, violent behavior, avoidance of people, and places and situations. All these symptoms may amount to specific disorders such as panic disorder or phobias [6,7].

The author thinks it imperative to mention "health anxiety" in relation to COVID-19 pandemic. Although in general, health anxiety is present up to varying degrees among the general population, it can become highly exaggerated during the COVID-19 pandemic. This results in misinterpretation or catastrophization, maximization of normal body sensations, or slightly altered body sensations. Even the areas of brain's processing of sensory information can get altered leading to a sense of heightened perception to pain or other unpleasant sensations. In addition, media also play a negative role in terms of hype of cases, presentation of inaccurate information, overdramatic, or theatrical presentation of cases resulting in increased anxiety $[6,7]$.

This can manifest as excessive apprehension or fear, seeking unnecessary or unwarranted health consultations or total avoidance of consultation, and hoarding medication such as hydroxychloroquine or ivermectin, and hoarding masks. It can even lead to selective targeting of particular communities or ethnic groups, a general lack of trust in the authorities, or health sector. All of these are bound to have disastrous implications as the mutual trust between the communities, the health-care sector and the public authorities will be lost [6,7]. Acute stress reaction can occur among the family member of a loved one who has died from the pandemic. Even post-traumatic stress disorder can occur in family members or doctors and nurses who have witnessed a lot of suffering and rather catastrophic deaths of victims of COVID-19 pandemic.

\section{Suicide and Intentional (Deliberate) Self-harm}

It is important to note the relationship between COVID-19 pandemic and general suicide and attempted/completed suicide rates among patients. Again there are bound to be cross-cultural and cross-country variations in suicide rate with Japan, paradoxically mentioning reduced suicide rates during the lockdown. This is because of the emergence of "protective" factors such as more time available with family, lessening of stress, less of performance anxiety, and less commuting to and fro from the workplace [8]. However, in most of the countries including India, suicide rates may increase. Globally, experts have warned that the impact of COVID-19 on economy, business enterprises, and joblessness can erode the self-esteem of people. In addition, factors such as, fear of contracting the illness, fear of quarantine/self-isolation, lack of specific medications/vaccines and the very high case fatality rate social isolation, building frustration, unpredictable and uncertain future, fear of poverty and homelessness, coupled with the wellknown risk factors (depression, and substance abuse), can escalate suicide like never before [9].

In a COVID-19 patient, the fear of passing on the disease to their loved one, the knowledge that there is no "sure cure" other than supportive care, social stigma, and discrimination attached to the disease, fear of dying alone, away from family are all contributing factors, not to exclude misinformation about the disease and dramatic media hype are factors which lead to suicide. The first suicide case in India was reported on February 12, 2020, wherein a man mistook his normal viral URTI to be COVID-19 infection and first isolated himself and then committed suicide $[9,10]$. Whatever the outcome of the pandemic may be, unfortunately it has succeeded in creating negative thoughts and hopelessness about the self, the world and the future. Furthermore, the health-care professionals are at high risk of attempting and committing suicide due to various factors such as fear of getting infection, unbearable stress, long and grueling working hours, and the psychological distress of having to watch COVID-19 patients die alone. Add to this, the social discrimination and even violence faced by the health-care professionals at the hands of the very society which they serve. No doubt they are driven to such desperate measures [9-11].

\section{Grief}

It can result from death of a loved one. It can also result from surviving alone or the "I alone survived" phenomenon wherein the individual is the only survivor whereas all other victims have died [12]. The individual patient may even undergo what is called as "Anticipatory Grief" wherein he contracts the disease, knows that his chances of survival are slim in view of his medical comorbidities or a rather malignant course of the disease $[12,13]$. 


\section{Somatoform Disorders}

People may manifest with "unexplained physical symptoms" which have no organic disease and physical findings/examination with no evidence of disease in a laboratory result. Such patient may even become "hypochondriac," wherein they insist having a particular disease affliction affecting a particular organ/system and may insist on getting themselves investigated for that particular disease. Such type of patients may overburden an already fragile and over-worked health care system leading to frustration among health-care seekers and health-care providers and a lack of mutual trust and respect [14].

\section{Substance Abuse}

During COVID-19 pandemic, people who are already actively using substances and are substance dependent may not have access to the drugs and unavailability of the substance may lead to severe craving, physical and psychological withdrawal symptoms, trying to deploy desperate means to gain access to the substance, leading to an increase in the number of thefts, robbery, shop-lifting, and other petty crimes. This will further tax the police and other security forces who are already burdened with maintaining law and order and making people obey the rules/regulation/norms during the lockdown [15]. With limited access to treatment adherence and detoxification centers during the pandemic, such people may behave irresponsibly and may act as potential vectors of virus transmission. They may already stretch their fragile finances to the utmost limit to procure the substance (alcohol, cannabis, and tobacco), which may leave little financial reserve for emergency. Substance abuse not only increases the propensity/risks for domestic violence and physical and sexual abuse but also facilitates and aggravates the COVID-19 illness by compromising the immune system $[15,16]$. An overdose of opioids can prove fatal in a patient with mild COVID-19 illness by causing respiratory depression. Similarly, smoking can exacerbate COPD and further compromise lung function in a patient with mildto-moderate COVID-19 disease. The WHO has issued a warning about alcohol use during the pandemic $[15,16]$.

\section{Domestic Violence and Physical/Psychological Abuse}

Perhaps the biggest brunt of COVID-19 pandemic has been an upsurge in the cases of domestic violence. Consider this scenario, "Imagine a man already having a propensity for violence in a closed confinement with his spouse with nothing to keep him occupied, with his work/business going down and frustration building up. How does he react? He, in all probability, may react by showing or exhibiting violence toward his spouse, children or even parents." In the above described scenario, a slight provocation or even a casual remark or request for participation in household chores can become a precipitating factor for perpetrating domestic violence [16,17]. The police who was readily available earlier, may be busy elsewhere and hence the fear of which used to act as a deterrent earlier, may not work now. With everyone under the lockdown, even social help (in the form of neighbors or NGOs) may not be available readily to the women. This can increase the risk of depression, intentional self-harm and erode the woman's self-esteem so much that she may be driven to attempt suicide [16,17].

\section{INTERVENTIONS}

Where do we go from here? How do we tackle this menace of not only the COVID-19 pandemic but also of the en masse psychological/mental health issues associated with this pandemic? The first step to solving any problem is to identify and delineate the goals. Here, the goals should be to minimize or mitigate the psychological distress associated with the pandemic and some sort of psychological rehabilitation post-pandemic [18].

The target populations on which we should focus include:

- The general population

- The frontline workers - health-care professionals, police, security personnel, etc.

- The At-Risk population - may include patients who have contracted COVID-19 illness and have survived/are fighting against infection, elderly or young adults harboring psychiatric comorbidities and children, and the disabled/ physically handicapped and those living in poverty $[18,19]$.

\section{TYPES OF INTERVENTION}

\section{Pharmacotherapy/drugs}

Patients with preexisting psychiatric disorders should be encouraged to continue taking the medication. If availability of medications and cost is an issue, long acting preparations with a once a day - schedule and cheaper alternative can be used to substitute the previous medications $[18,19]$. Pharmacotherapy in combination with other modalities of treatment is by far the first choice in patients harboring severe psychiatric disorders.

\section{Education}

The mental health education about the psychological impacts of any pandemic to the general population is most important. It should be emphasized that psychological reaction to a crises as large as this one is expected and is "okay" to have. The public must be motivated to adopt strategies for disease prevention and health promotions must be encouraged to take all precautions and follow the norms/rules of the lockdown for their own safety as well as of others. It should be emphasized that despite partial or a complete lockdown, there are still ways of connecting with each other (telephonically, through Skype, video calls, etc.) [19]. The people should be encouraged to tap into their existing strengths and be helped to "fit into their new roles."

\section{Supportive Psychotherapy}

It can be offered in an individual or a group setting for a particular subset of a population such as healthcare workers. It can be 
carried out once a week in small groups of 7-10 individuals. It is generally aimed at symptom relief and behavioral modification (to minimize maladaptive behavior like absenteeism) and to enhance productivity. Supportive psychotherapy, if diligently used, can help in improving the workers self-esteem, ego functioning and adaptive skills, which, in turn, would translate into work productivity $[19,20]$.

\section{Crisis Intervention}

In the background of this pandemic, a crisis can be defined by three factors - negative events (a loved one or the client himself contracting the COVID-19 infection), feeling of hopelessness associated with this negative event (the feeling that he/she may not make it, may die alone), and unpredictable events (sudden deterioration in physical condition of his own/a loved one's). Such people who experience crises are overwhelmed by feelings of helplessness, powerlessness, and a lack of control. Crises intervention must be done within 6-24 h of a negative event to be effective [19-21]. This intervention is best done individually or in family settings, either online or face to face, while maintaining appropriate social distancing [20,21]. The aim should be to tap into the client's problem solving abilities and to restore him to his previous level of functioning. Clients likely to benefit from crisis intervention include, doctors when one of them contracts this disease, nurses who have lost a colleague to the pandemic, quarantined individuals, and family member whose loved one has contracted the COVID-19 and has not survived/is unlikely to survive $[20,21]$.

\section{Cognitive Behavioral Therapy}

This therapy focuses on the correction of negative automatic thoughts and cognitive distortions, followed by correction of underlying dysfunctional cognitive schemas [20,21]. In the COVID-19 pandemic, observable behaviors such as bulk purchasing, hoarding of medications, excessive cleaning may underlie negative automatic thoughts such as "if I am not cleaning enough, I am not doing enough," "I am losing control," "if I do not over-prepare, I may be the next victim," etc. Accompanied by these negative automatic thoughts are the cognitive distortions such as maximization, minimization, and catastrophization. It should be emphasized into the client's mind they are empowered to pursue what they value or is important to them. Therefore, acting according to their values will help them improve their self-efficacy and help them feel better about themselves, give them some sense of control over their lives although they cannot fully control the virus or what happens to them $[20,21]$.

\section{Other Therapies}

Other therapies such as rational emotive behavioral therapy, eclectic therapy, brief dynamic psychotherapy, all play a role in this COVID-19 pandemic [21].

\section{GENERAL POINTS TO REMEMBER}

- Most of us have already been taken down to the "survival level" of Maslow's hierarchy of needs. Earlier our motto was "Not only to survive but also to thrive." Now it is "Survive through this." Once the pandemic is over then if we have actually managed to survive, we can think about "thriving." However, we must remember that our priorities and the "new normal" in the post pandemic era will be different from the "old normal" [21,22]

- Doing something hard is tough, doing nothing is harder/ tougher: For the younger generation which is restless, sitting at home quietly and doing nothing appears to be a big waste of both time as well as their "potential abilities" [21,22]. Although, most of the upper-middle-class and upper-class older generation people may be content to sit at home spending quality time together, the younger generation is rather impatient, want to achieve everything in a short time and want immediate sense gratification. Therefore, trying a new hobby or a past time such as sketching, painting, developing a habit of reading, writing, and cooking are some of the productive leisure activities which they can resort to during the COVID-19 pandemic should be encouraged [22]

- Changing the profession/taking up a new profession temporarily: This may be an option available only to a selected few. The author's own friend, a community medicine professor has changed his profession. He has now started business (both wholesale and retail) of supplying masks, face-shields, PPE to medical student and resident doctors. The idea is to do a business or resort to a livelihood which will hold our economy stable during the COVID-19 crisis [23]. Stitching face-masks (of cotton) which can be washed and re-used is another option. However, this should not be done impulsively or carelessly, rather it should be a well-thought of and a planned endeavor to tide over the crisis

- Telephonic/audio-video online availability of mental health services: The various intervention and psychotherapies described earlier in this article may have to be done online rather than face to face. However, many patients may not feel comfortable with the audio-video counseling. Children and adolescents may be more resistant since it deprives them the opportunity to connect with their therapist in real-time and hence they may perceive it as an assault on their autonomy, since it hampers their ability to seek therapy outside of home. Hence, they may not respond well. Adults and the elderly, who are stable and have had a long term therapy with their therapist/psychiatrist may not be so resistant and may do well with the audio-video format [24]

- Helpline services: Twenty-four hours helplines should be made available for victims of domestic violence, suicide victims, and even for substance users. Although, the services of rehabilitation centers may not be available now, the organization like Alcohol Anonymous is doing a commendable job by offering some respite to the people. NGOs need to step in aggressively $[25,26]$ 
- Be grateful and thankful for what you have: While we sit and wait it out we must be thankful and grateful for what we have. Spending quality time with loved ones, getting opportunity to explore our hidden potentials, reading, meditation, being kind to one another, and conversation with family members and friends are some of the activities which may keep us "sane" during the COVID-19 pandemic. Observing nature as it blooms and taking comfort and even deriving joys from it can reduce stress levels [27].

\section{CONCLUSION}

While, the world is amidst the most devastating deadly pandemic, it is important for people to keep all their mental faculties intact and gather their wits about them, to survive this pandemic. Although, isolation, home quarantine, and social distancing are important, it is equally important to emphasize measures to combat or tackle the invisible psychological trauma resulting from this pandemic. Treating only the physical symptoms without considering the psychological implications will lead to an unproductive or a relatively less productive society in post-pandemic period with long-term devastating consequences. Perhaps, it is time to launch a specific website to address psychological and psychosocial issues.

\section{REFERENCES}

1. Montemurro N. The emotional impact of COVID-19: From medical staff to common people. Brain Behav Immun 2020;87:23-4.

2. COVID-19 Corona Virus Pandemic. Graphs-Countries Death RateSymptoms-Transmission. Available from: http://www.worldometers.info. [Last accessed on 2020 Aug 21].

3. Asmumdson GJ, Taylor S. Corona phobia: Fear and the 2019-nCoV outbreak. J Anxiety Disord 2020;70:102196.

4. Hoof EV. Lockdown is the World's Biggest Psychological Experiment and we will Pay the Price. World Economic Forum; 2020. Available from: https:// www.weforum.org/agenda/2020/04/this-is-the-psychological-side-of-thecovid-19-pandemic-that-were-ignoring. [Last accessed on 2020 Aug 18].

5. Kang L, Li Y, Hu S, et al. The mental health of medical workers in Wuhan, China dealing with the 2019 novel coronavirus. Lancet Psychiatry 2020;7:e14.

6. Shigemura J, Ursano RJ, Morganstein JC, et al. Public responses to the novel 2019 coronavirus (2019-nCoV) in Japan: Mental health consequences and target populations. Psychiatry Clin Neurosci 2020;74:281-2.

7. Shanafelt T, Ripp J, Trockel M. Understanding and addressing sources of anxiety among health care professionals during the COVID-19 pandemic. JAMA 2020;323:2133-4.

8. Tanno S. Japan's Suicide Rate Falls by a Fifth during Coronavirus Pandemic. Available from: https://www.dailymail.co.uk/news/article-8320531/Japanssuicide-rate-falls-fifth-coronavirus-pandemic.html. [Last accessed on 2020 Aug 18].

9. Gunnell D, Appleby L, Arensman E, et al. Suicide risk and prevention during the COVID-19 pandemic. Lancet Psychiatry 2020;7:468-71.

10. Goyal K, Chauhan P, Chhikara K, et al. Fear of COVID 2019: First suicidal case in India! Asian J Psychiatr 2020;49:101989

11. Cheung YT, Chau PH, Yip PS. A revisit on older adults suicides and severe acute respiratory syndrome (SARS) epidemic in Hong Kong. Int J Geriatr Psychiatry 2008;23:1231-8.

12. Weir K. Grief and COVID-19: Mourning our Bygone Lives. American Psychological Association. Available from: https://www.apa.org/news/ apa/2020/04/grief-covid-19. [Last accessed on 2020 Aug 20].

13. Wallace CL, Wladkowski SP, Gibson A, et al. Grief during the COVID19 pandemic: Considerations for palliative care providers. J Pain Symptom Manage 2020;60:e70-6.

14. Colizzi M, Bortoletto R, Silvestri M, et al. Medically unexplained symptoms in the times of COVID-19 pandemic: A case-report. Brain Behav Immun Health 2020;5:100073.

15. Hein I. Alcohol Abuse Agitated by COVID-19 Stirring Liver Concerns. Available from: https://www.medscape.com/viewarticle/930039. [Last accessed on 2020 Aug 21].

16. Catala-Minana A, Lila M, Oliver A, et al. Contextual factors related to alcohol abuse among intimate partner violence offenders. Subst Use Misuse 2017;52:294-302.

17. Campbell AM. An increasing risk of family violence during the Covid-19 pandemic: Strengthening community collaborations to save lives. Forensic Sci Int Rep 2020;2:100089.

18. Ho CS, Chee CI, Ho RC. Mental health strategies to combat the psychological impact of COVID-19 beyond paranoia and panic. Ann Acad Med Singap 2020;49:155-60.

19. Duan L, Zhu G. Psychological interventions for people affected by the COVID-19 epidemic. Lancet Psychiatry 2020;7:300-2.

20. Mental Health and Psycho Social Consideration during the COVID-19 Outbreak. World Health Organization. Available from: https://www.who.int/ publications/i/item/WHO-2019-nCoV-MentalHealth-2020.1. [Last accessed on 2020 Aug 19].

21. Mental Health in the Times of COVID-19 Pandemic. Guidance for General Medical and Specialized Mental Health Care Setting. National Institute of Mental Health and Neuroscience; 2020. Available from: https://www. mohfw.gov.in/pdf/COVID19Final2020ForOnline9July2020.pdf. [Last accessed on 2020 Aug 24].

22. Wang C, Pan R, Wan X, et al. Immediate psychological responses and associated factors during the initial stage of the 2019 coronavirus disease (COVID-19) epidemic among the general population in China. Int J Environ Res Public Health 2020;17:1729.

23. Tsai J, Wilson M. COVID-19: A potential public health problem for homeless populations. Lancet Public Health 2020;11:e186-7.

24. Liu S, Yang L, Zhang C, et al. Online mental health services in China during the COVID-19 outbreak. Lancet Psychiatry 2020;7:e17-8.

25. Zhou X, Snoswell CL, Harding LE, et al. The role of telehealth in reducing the mental health burden from COVID-19. Telemed J E Health 2020;26:377-9.

26. Xiao C. A novel approach of consultation on 2019 novel coronavirus (COVID-19)-related psychological and mental problems: Structured letter therapy. Psychiatry Investig 2020;17:175-6.

27. Goldstein M. Benefits of Gratitude during COVID-19. Available from: https://www.psychiatrictimes.com/view/benefits-gratitude-duringcovid-19. [Last accessed on 2020 Apr 24].

Funding: None; Conflict of Interest: None Stated.

How to cite this article: Chhabra S. The emotional and psycho-social consequences of coronavirus disease- 19 pandemic - A glimpse into the postpandemic society. East J Med Sci. 2020;5(3):48-52.

Doi: 10.32677/EJMS.2020.v05.i03.001 